\title{
Retail lighting and packaging influence consumer acceptance of fluid milk
}

\author{
H. L. Potts, K. N. Amin, and S. E. Duncan ${ }^{1}$ \\ Department of Food Science \& Technology, Virginia Polytechnic Institute and State University (Virginia Tech), Blacksburg 24061
}

\begin{abstract}
Little is known about the effect of retail light-emitting diode (LED) exposure on consumer acceptance of milk. The study objective was to determine effects of fluorescent and LED lighting under retail storage conditions on consumer acceptance of milk. Consumer acceptance of milk stored under retail conditions was determined through sensory evaluation ( 2 studies; $\mathrm{n}=150+$ each) and analytical measures (dissolved oxygen, secondary oxidation products, riboflavin retention). Study 1 evaluated milk stored in high-density polyethylene (HDPE) packages for $4 \mathrm{~h}$ under LED light (960 lx). Commercially available HDPE package treatments included translucent HDPE (most commonly used), white HDPE [low concentration $(1.3 \%) \mathrm{TiO}_{2}$ ], and yellow HDPE; in addition, HDPE with a higher $\mathrm{TiO}_{2}$ concentration (high white; $4.9 \% \mathrm{TiO}_{2}$ ) and a foil-wrapped translucent HDPE (control) were tested. Translucent and control packages also were tested under fluorescent light. Study 2 evaluated polyethylene terephthalate (PET) packages for $4 \mathrm{~h}$ under fluorescent and LED light (1,460 lx). The PET packaging included 2 treatments (medium, $4.0 \%$ $\mathrm{TiO}_{2}$; high, 6.6\% $\mathrm{TiO}_{2}$ ) as well as translucent HDPE (exposed to fluorescent), clear PET (fluorescent and LED), and light-protected control. Overall mean acceptability of milk ranged from "like slightly" to "like moderately" with significantly lower acceptability for milk exposed to fluorescent light. Milk in HDPE and PET packages had comparable overall acceptability scores when exposed to LED light. Only the fluorescent light condition (both PET and HDPE) diminished overall acceptability. Fluorescent light exposure negatively influenced flavor with significant penalty $(2.0-2.5$ integers) to overall acceptability of milk in translucent HDPE and clear PET. The LED also diminished aftertaste of milk packaged in translucent HDPE. Changes in dissolved oxygen content, as an indication of oxidation, supported the observed differences in consumer acceptance of milk stored under fluorescent and LED light. Consumers like the flavor of fresh milk, which can
\end{abstract}

Received June 28, 2016.

Accepted September 30, 2016.

${ }^{1}$ Corresponding author: duncans@vt.edu be protected by selecting appropriate packaging that blocks detrimental light wavelengths.

Key words: milk, oxidation, sensory, light-emitting diode (LED)

\section{INTRODUCTION}

Milk consumption in the United States has been declining for several decades. Overall, fluid milk sales decreased $5.2 \%$ in 2015 alone (Bauer, 2016). Part of the reason for this decline is increasing beverage competition in the retail case with alternative plant-based milk beverages. This decline may also be attributed to consumer experiences with fresh milk of low flavor quality due to light-induced oxidation reactions. As a result of light exposure in the retail case, milk flavor quickly deteriorates from the sweet, bland flavor of fresh milk, with a clean, pleasing aftertaste (Alvarez, 2009). The oxidation reaction alters milk flavor, with milk becoming less sweet and developing a cardboard flavor (Alvarez, 2009) as a variety of volatile compounds are generated that overwhelm fresh milk flavor. Simultaneously, milk nutrients are affected by oxidation reactions, including vitamins (riboflavin, $\mathbf{R} \mathbf{b}$; vitamin A), lipids, and proteins.

Flavor is one of the most important characteristics that influences repeat purchase behavior (Schifferstein et al., 2013). Untrained consumers can detect lightoxidized off-flavor in $2 \%$ milk exposed to fluorescent light after as little as 54 to $120 \mathrm{~min}$ of fluorescent light exposure (2,000 lx; Chapman et al., 2002), which is well within the timeframe that packaged milk is displayed within the dairy retail case. Heer et al. (1995) reported a threshold of detection for light-oxidized flavor in $2 \%$ milk at $150 \mathrm{~min}$ (fluorescent; 1,100-1,300 lx). Only a few studies have reported how light-induced flavor affects consumer acceptance, however. Heer et al. (1995) reported mean acceptability scores of light-exposed milk (at threshold of detection) for middle school students as "dislike slightly" ( mean $=4.2 ; \mathrm{n}=17$ ), college students as "neither like nor dislike" (mean $=5.2 ; \mathrm{n}=$ 30 ), and adults as less than "like slightly" ( mean $=5.6$; $\mathrm{n}=25$ ). Walsh et al. (2015) found that consumers (n $=41$ college students; 33 female) expressed decreased acceptability of light-oxidized milk (2\% milkfat; 375 
$\mathrm{lx}$ at the shoulder of the HDPE package; $1,738 \mathrm{~lx}$ in lightbox) after $8 \mathrm{~h}$ of storage, with mean scores of 5.85 \pm 2.23 (less than "like slightly"; 95\% CI: 5.15-6.56) for light-exposed milk compared with $7.2 \pm 1.05$ ("like moderately"; 95\% CI: 6.86-7.53) for light-protected milk. Arnade et al. (2013) reported an overall acceptability of 5.7 (less than "like slightly") for milk purchased directly from the retail case $(\mathrm{n}=48$ college students). These studies, although they indicate that consumers negatively respond to light-induced flavor, are limited by the small sample size.

The adverse effect of fluorescent light on milk quality has been well documented and the subject of primary research and reviews (Chapman et al., 2002; Mestdagh et al., 2005; Duncan and Webster, 2010; Johnson et al., 2015; Brothersen et al., 2016). Many retailers are switching from fluorescent lights to more energyefficient light-emitting diode (LED) lights to meet US Department of Energy mandated energy reduction requirements. However, milk oxidation under LED light is a new area of study that warrants further attention. Brothersen et al. (2016) showed that LED light intensity $(4,000 \mathrm{~lx})$ caused less extensive nutritional changes from light-induced oxidation in $1 \%$ milk than fluorescent light $(2,200 \mathrm{~lx})$ after $24 \mathrm{~h}$ of light exposure. Consumer $(\mathrm{n}=90)$ overall liking scores for milk $(1 \%$ milkfat; vitamin A and D added) stored for $24 \mathrm{~h}$ under LED and fluorescent lighting-exposed samples were 5.4 (just above "neither like nor dislike"), whereas milk stored in the absence of light had significantly higher acceptability (mean $=6.3$; "like slightly"). Milk for this experiment was processed at the university creamery, packaged into high-density polyethylene (HDPE) half gallon containers, and exposed to lighting using light boxes (Brothersen et al., 2016). Martin et al. (2016), using freshly processed milk attained directly from several processing plants, reported the effect of LED light exposure $(1,200 \mathrm{~lx} ; 4 \mathrm{~h}$ ) in a light box on consumer ( $\mathrm{n}$ $=150$ ) acceptance of both nonfat and $2 \%$ milk. Fresh nonfat LED-exposed milk had an overall acceptability score of 5.7 ("like slightly") in comparison to the control, with a score of 6.6. A similar trend was observed with $2 \%$ milk. As milk aged ( $14 \mathrm{~d}$ ), the influence of the light-induced flavor was less influential on acceptability.

Date coding on milk packages indicate the time frame through which the product will taste and smell good (Keith, 2005; USDA, 2015). When a consumer purchases milk, the code is often used in the decision. Martin et al. (2016) reported that consumers had a more negative reaction to milk illustrating effects of light exposure than they did to milk with early stages of bacterial growth as products approached code. Consumer experience with milk (appearance, odor, taste) at the time of opening and first use contributes to their perception of freshness and, indirectly, in their trust and confidence in the product (Schifferstein et al., 2013), the manufacturer, as well as the dairy industry. Their decision to repeat purchase is influenced by this experience. The effect of light on fluid milk flavor and aftertaste contributes to freshness perception and overall acceptability, especially for milk packaged in traditional translucent HDPE and even for some commercially utilized HDPE packages with light protective additives. Although code date is typically established based on microbial spoilage, consumers may not believe the (light-exposed) milk they just purchased, which is well within code date, is fresh or they may think that fresh milk does not taste good.

The majority of milk is currently packaged in HDPE. However, translucent HDPE packages provide insufficient protection against light exposure and allow for extensive light-induced oxidation to occur in milk (Brothersen et al., 2016; Martin et al., 2016). Polyethylene terephthalate (PET), with higher oxygen barrier properties, may offer a higher degree of protection against light-induced oxidation because oxygen availability is limited to the dissolved oxygen (DO) in the milk and the package headspace (Potts et al., 2016).

Pigmentation of packaging materials provides additional protection by blocking certain light wavelengths from reaching milk inside the package. White (1985) identified that consumers preferred white and cream pigmented plastic milk packaging more than translucent or yellow. At the time of the study (White, 1985), most consumers surveyed $(74 \%)$ were not concerned about whether they could see the product; they had equal concern about flavor and nutritional value of the milk. Knowledge is lacking about consumer acceptance of milk packaged in PET and milk stored in LED-lit retail conditions.

The objectives of this experiment were to characterize consumer acceptance of $2 \%$ milk when (1) exposed to retail lighting (LED, fluorescent) conditions and (2) in packaging (HDPE, PET) with different light blocking properties. A unique feature of this study is the use of commercially produced retail dairy cases, equipped with LED and fluorescent lighting, to effectively mimic the lighting conditions under which consumers select their milk for purchase.

\section{MATERIALS AND METHODS}

\section{Experimental Design Overview}

This experiment was completed as 2 studies. Each study assessed acceptability and quality of milk after $4 \mathrm{~h}$ of refrigerated exposure to LED and fluorescent retail lighting $(3,500 \mathrm{~K})$ conditions. The first study 
used commercial and experimental HDPE packaging at $960 \mathrm{~lx}$. The second study focused on PET packaging at 1,460 lx. This range of light intensities is common in retail dairy cases. Packaging treatments provided a broad range of light barrier properties with translucent HDPE package included in both studies to provide comparison. Analytical assessments and sensory testing methods were completed using the same protocols for both studies.

\section{Milk Packaging and Treatment Conditions}

Milk packaging was characterized based on color measurements and wall thickness (Table 1). Color was measured in triplicate based on the CIE $\mathrm{L}^{*} \mathrm{a}^{*} \mathrm{~b}^{*}$ system as measured by a Konica Minolta CR-300 Chroma Meter (Tokyo, Japan); a representative piece of packaging was placed against a white standard color tile for measurement. Wall thickness was measured on representative packages (triplicate) using an electronic digital caliper (Starrett 799A series, Athol, MA); measurements were taken at several locations on the package and averaged.

Four different HDPE treatment packages (1.89 L) were prepared for the first study by standard extrusion blow-molding procedures (Ampacet, Tarrytown, NY). Package treatments (4 treatments and a control) included commercially available translucent HDPE, commercial white HDPE (low white; $1.3 \% \mathrm{TiO}_{2}$ ), and yellow HDPE with a commercial yellow pigment masterbatch). An experimental (not commercially available) white package (high white; $4.9 \% \mathrm{TiO}_{2}$ ) was also included. Additionally, the translucent HDPE package, wrapped in foil and plastic, served as the light-protected control. All filled packages ( $\mathrm{n}=75$ total; 15 packages for each treatment +15 control packages) were exposed to LED light (960 lx); the translucent HDPE control packages were placed under fluorescent light at the same intensity.
In the second study, both PET $(2 \mathrm{~L} ; \mathrm{n}=5)$ and HDPE packages $(1.89 \mathrm{~L} ; \mathrm{n}=1)$ were used because PET packages are not common in commercial use for fluid milk. Bottles for this study were blow molded from resin using standard injection blow-molding procedures, yielding a shape like a standard 2-L soda bottle (PTI Technologies, Holland, OH). Two white PET (medium $=4.0 \% \mathrm{TiO}_{2}$; high $=6.6 \% \mathrm{TiO}_{2}$ ) and a clear PET bottle were used for the study. The clear PET bottle, wrapped in foil and plastic, functioned as the light-protected control package. All PET packages were exposed to LED light at 1,460 lx. The translucent HDPE (1.89 L) packaging from study 1 was included to allow for comparison between the 2 studies; both the translucent HDPE and the clear PET were exposed to fluorescent light at an equivalent intensity (1,460 lx).

The 2 studies were completed within one month of each other. Milk for each study was obtained from a commercial fluid milk processing plant in Virginia immediately before the study (approximately $24 \mathrm{~h}$ ). High temperature, short time pasteurized fluid milk (2\% milkfat, vitamin $\mathrm{A}$ and $\mathrm{D}$ fortified) packaged in translucent 1.89-L HDPE packages (study 1: $\mathrm{n}=90$; study $2: \mathrm{n}=80$ ) was obtained from a local dairy processor immediately after processing and transported in light-blocking coolers with ice for light and temperature protection (estimated $2-4^{\circ} \mathrm{C}$ ) to the Virginia Tech pilot plant (Blacksburg, VA). Milk was rapidly transferred into package treatments under a clean-fill positive flow laminar hood (Thermo Fisher Scientific, Waltham, MA), capped by hand, and stored in a dark walk-in retail case (model 3800, HillPhoenix, Chesterfield, VA) until transferred to the lighted retail case.

Packaged milk for the first study was placed in a closed door retail case (model ONRB4, HillPhoenix, Chesterfield, VA) to meet targeted light intensity at $960 \mathrm{~lx}$. This case was specifically designed by the manufacturer to have a 4 -ft section for LED and a

Table 1. Color ${ }^{1}$ and wall thickness characterization ${ }^{2}$ of high-density polyethylene (HDPE) and polyethylene terephthalate (PET) packages

\begin{tabular}{|c|c|c|c|c|c|}
\hline \multirow[b]{2}{*}{ Packaging material } & \multirow[b]{2}{*}{ Visual appearance $\left(\% \mathrm{TiO}_{2}\right)$} & \multirow{2}{*}{$\begin{array}{c}\text { Wall thickness }(\mathrm{mm}) \\
\text { Mean } \pm \mathrm{SE}\end{array}$} & \multicolumn{3}{|c|}{ Color $^{1}$} \\
\hline & & & $\mathrm{L}^{*}$ & $a^{*}$ & $b^{*}$ \\
\hline Commercial & Translucent $\left(0 \% \mathrm{TiO}_{2}\right)^{3}$ & $0.54 \pm 0.03$ & 89.03 & 0.78 & -2.65 \\
\hline Commercial & White $\left(1.3 \% \mathrm{TiO}_{2}\right)$ & $0.64 \pm 0.03$ & 96.46 & 0.15 & -0.74 \\
\hline Experimental & White $\left(4.9 \% \mathrm{TiO}_{2}\right)$ & $0.57 \pm 0.05$ & 97.48 & -0.05 & -0.52 \\
\hline \multirow{3}{*}{$\begin{array}{l}\text { Commercial } \\
\text { PET }\end{array}$} & Yellow (no additive characterization available) & $0.63 \pm 0.04$ & 87.95 & -12.31 & 69.76 \\
\hline & White $\left(4.0 \% \mathrm{TiO}_{2}\right)$ & $0.35 \pm 0.03$ & 96.31 & 0.17 & -0.75 \\
\hline & White $\left(6.6 \% \mathrm{TiO}_{2}\right)$ & $0.33 \pm 0.01$ & 97.20 & 0.01 & -0.37 \\
\hline
\end{tabular}

${ }^{1} \mathrm{~L}^{*}=$ black $(0)$ to white $(100) ; \mathrm{a}^{*}=$ green to red; $\mathrm{b}^{*}=$ blue to yellow.

${ }^{2} \mathrm{n}=3$.

${ }^{3}$ Measured against a standard white tile. 
separate 4-ft section for fluorescent lighting to accommodate comparative studies. For the second study, an additional retail case (open case; model O5DM, HillPhoenix; 3500K LED lights) was included to provide sufficient LED light intensity locations at 1,460 lx. In both studies, 1 to 2 packages of each treatment plus control were placed in the case at the same time. After $4 \mathrm{~h}$ of continuous light exposure, milk was removed from the retail case, samples for analytical measures of quality were collected, and packages returned to the dark walk-in retail case for storage until transport to the sensory evaluation laboratory at North Carolina State University (Raleigh, NC). Due to limited lighting locations at the targeted light intensity, light exposure was completed for the targeted light-exposure duration $(4 \mathrm{~h})$ over $3 \mathrm{~d}$ to achieve the targeted number of packages per treatment and control.

\section{Analytical Measures of Milk Quality}

Sampling Plan and Sample Storage Conditions. Fresh milk (as received at VT pilot plant) was sampled ( $\mathrm{n}=3$ packages) for microbiological analyses, thiobarbituric acid reactive substances (TBARS) assay $(10 \mathrm{~mL}), \mathrm{Rb}$ degradation assay $(30 \mathrm{~mL})$, and DO. After light exposure, milk in all treatment packages was measured for dissolved oxygen content immediately after opening each package. Samples were collected from every treatment package for TBARS assay $(10 \mathrm{~mL})$ and $\mathrm{Rb}$ degradation assay $(30 \mathrm{~mL})$. The TBARS and $\mathrm{Rb}$ degradation samples were transferred to polypropylene tubes and frozen $\left(-20^{\circ} \mathrm{C}\right.$, Harris Environmental Systems, Andover, MA) until analysis could be completed. For each assay, one sample was analyzed from each treatment bottle $(\mathrm{n}=15$ per treatment +15 control packages) and fresh milk, as received from the processing plant, was analyzed in triplicate for both studies, unless otherwise described.

Microbiological Quality. Fresh milk was tested for microbiological quality, in triplicate, at the beginning of each study to ensure that any quality changes were due to treatment conditions and not a result of poor quality milk. Growth of aerobic organisms was measured by a standard plate count by standard methods (Laird et al., 2004) on Petrifilm Aerobic Count Plates $\left[32 \pm 1^{\circ} \mathrm{C}\right.$ (SD), $48 \pm 3 \mathrm{~h}]$ and Coliform Count Plates $\left(37 \pm 1^{\circ} \mathrm{C}\right.$, 24 h; 3M, St. Paul, MN).

Dissolved Oxygen Content. Dissolved oxygen content was measured using a handheld DO meter (LDO101, Hach, Loveland, CO). The meter probe was sanitized before beginning and between each measurement. The DO was measured immediately after opening each package to prevent atmospheric oxygen from influencing the results. The DO was also measured before any other sample collection to prevent oxygen incorporation from package agitation.

TBARS Assay. Frozen samples were thawed in an ice water bath with light protection within $12 \mathrm{~h}$ of analysis and analyzed for levels of secondary oxidation byproducts of fatty acids using TBARS assay. Collection and analysis was completed as described (Spanier and Traylor, 1991; Johnson et al., 2015), except that samples $(1 \mathrm{~mL})$ were not diluted before analysis.

Riboflavin Degradation Assay. Frozen samples were thawed in an ice water bath with light protection within $12 \mathrm{~h}$ of analysis. Riboflavin degradation assay was completed under limited light exposure using a modified fluorometric assay (AOAC Method 970.65; AOAC International, 1995) as described by Webster et al. (2009). Fluorescence was measured on a Shimadzu RF-1501 spectrofluorophotometer (Shimadzu Scientific Instrument Inc., Columbia, MD).

\section{Sensory Evaluation}

Milk was transported to the North Carolina State University (NCSU) Sensory Services Center (Raleigh, $\mathrm{NC}$ ) in coolers with ice, providing light and temperature protection, within $2 \mathrm{~d}$ of light-exposure completion. Once milk was received at NCSU, it was stored in a dark walk-in refrigerated retail case (UDS-4/Brown, Salisbury, NC) until consumer sensory panels were completed, within $48 \mathrm{~h}$ of transport.

On the day of sensory testing, 4 gallons $(15.1 \mathrm{~L})$ of milk from individual bottles $(\mathrm{n}=8)$ for each treatment were commingled into 5 -gallon $(18.9 \mathrm{~L})$ insulated beverage coolers (Igloo Products Corp., Katy, TX) and commingled milk $(89 \mathrm{~mL})$ was poured into 3-digit coded 177-mL (6-oz) Styrofoam sample cups. By commingling all the milk from the same package treatment (or control) before preparing the sensory samples, any variability due to different duration of post-light exposure storage in the darkened conditions (up to $3 \mathrm{~d}$ ) was resolved. Samples were maintained at $<10^{\circ} \mathrm{C}$ and protected from light during preparation and serving. Milk was served to the panelists at 8 to $12^{\circ} \mathrm{C}$ (just above refrigeration temperatures), as standard protocol for the NCSU Sensory Service Center, to allow for the optimal flavor profiling (Alvarez, 2009).

All participants, screened from a pool of approximately 7,500 adults in the Raleigh area, were frequent consumers of milk (at least 2-3 times per month). Participants completed a digital consent form before participating in the sensory evaluation. Panelists (study 1 $=154$, study $2=157$ ) tasted all 6 samples of milk in a randomized complete block design and evaluated each sample for liking (overall acceptability, appearance, aroma, flavor, mouthfeel/thickness, aftertaste), aftertaste 
intensity, and freshness perception on a 9-point hedonic scale $(1=$ dislike extremely; $9=$ like extremely). Two just-about-right (JAR) questions were also asked to see how panelists rated their perception of flavor and mouthfeel/thickness/viscosity on a JAR scale $(1$ or $2=$ too little, $3=$ just right, 4 or $5=$ too much).

\section{Statistical Analyses}

The analysis of sensory data included liking attributes and JAR attributes. Liking attributes evaluated for differences $(P<0.05)$ using ANOVA and Fisher's LSD in XLSTAT (Addinsoft, New York, NY). The JAR attributes were analyzed for differences $(P<0.05)$ using the $\mathrm{k}$ proportion test in XLSTAT (Addinsoft). The Penalty Analysis function in XLSTAT was used to determine the influence of JAR attributes on overall acceptability.

Analytical tests (TBARS, Rb, DO) were completed in triplicate or higher for all treatments. Outliers were removed from the data set at $95 \%$ confidence using Dixon's Q test (Cochran and Snedecor, 1980). Oneway ANOVA measured significant $(P<0.05)$ changes in oxidation (JMP Pro 11, SAS Institute Inc., Cary, NC). Means and standard deviation were calculated for TBARS, Rb degradation, and DO (Microsoft Excel for Mac 2011, version 14.5.8, Microsoft Corporation, Redmond, WA).

\section{RESULTS AND DISCUSSION}

Fresh milk was of excellent microbial and chemical quality. Therefore, we attributed any changes in consumer acceptance, JAR characteristics, and milk quality to experimental conditions (lighting, packaging) influencing the oxidative stability of milk.

\section{Sensory Evaluation}

Consumer Demographics. Participants were mostly female $(59 \%)$ and white $(60 \%)$ with most others self-identifying as Asian (19\%) or black/African American $(17 \%)$. The age range was distributed broadly from 18 to $65 \mathrm{yr}$ of age though slightly skewed to the young adult audience ( $41 \%$ between 18 and $36 \mathrm{yr}$ ). The majority of participants $(75 \%)$ consumed milk 2 or more times per week. Approximately half (study $1=50 \%$; study $2=48 \%$ ) consumed $2 \%$ milk more frequently than other varieties of milk. Most participants were also frequent purchasers of milk, with about $50 \%$ of participants purchasing milk from the grocery store at least once a week (study 1: 49\%; study 2: $50 \%$ ). This consumer study provided valuable insight for the typi- cal expectations of milk quality for the milk-consuming population in this country.

Consumer Acceptability. Overall acceptability of a product provides information about how well a product is liked by consumers. When compared against other products, the relative acceptance scores may be used to infer preference (Meilgaard et al., 2007). Figure 1 illustrates the mean overall acceptability scores for both studies, providing a comparison of overall acceptability across lighting and packaging. In this study, the light-protected control products (PET, HDPE) were considered the best target, as this is the baseline product that had no light exposure and consequently little to no light-induced oxidation. The HDPE and PET packaging under LED lighting functioned well with no significant differences for overall acceptability for milk after $4 \mathrm{~h}$ of light exposure. Mean scores were above or close to 6.5 (between "like slightly" and "like moderately") on the 9-point hedonic scale. A telling contrast, however, is the significant decrease in overall acceptability $(P<0.05)$ of milk packaged in translucent HDPE and clear PET exposed to fluorescent light. Overall acceptability fell to just above "like slightly" or lower $(P<0.05)$, suggesting that consumers would prefer milk in light-protective packages and that lowlevel LED light was less detrimental over short time exposure. The histogram (Figure 2) for overall acceptability provides additional insight as to the influence of protecting milk from light. Whereas differences in mean scores suggest relatively little downward shift in overall acceptability, the proportion of consumers who chose a score of 4 or lower (dislike region) is much higher for milk in translucent HDPE or clear PET under fluorescent light. In addition, it is also possible to see that light-protected milk trends further to the right under both fluorescent and LED lighting, with more consumers choosing the higher hedonic values of 8 and 9 ("like very much" or "like extremely").

Typical overall acceptability ratings for most foods on the market fall between 5.5 and 7.5 , with a rating score above 7 considered good, 7.5 very good, and 8 or above as above expectations (Peryam, 1957). A mean score of 7.0 or higher is often suggested as a goal for product development or as a potential indicator for product success; however, many products that meet this goal are not successful so such a metric cannot be used alone. As a biological fluid, changes in milk freshness still occur under optimum storage conditions over time. Therefore, it is important that consumers have access to the freshest tasting milk available at the time they make the initial purchase. An important role of packaging is to protect fresh milk flavor from point of processing through purchase. 

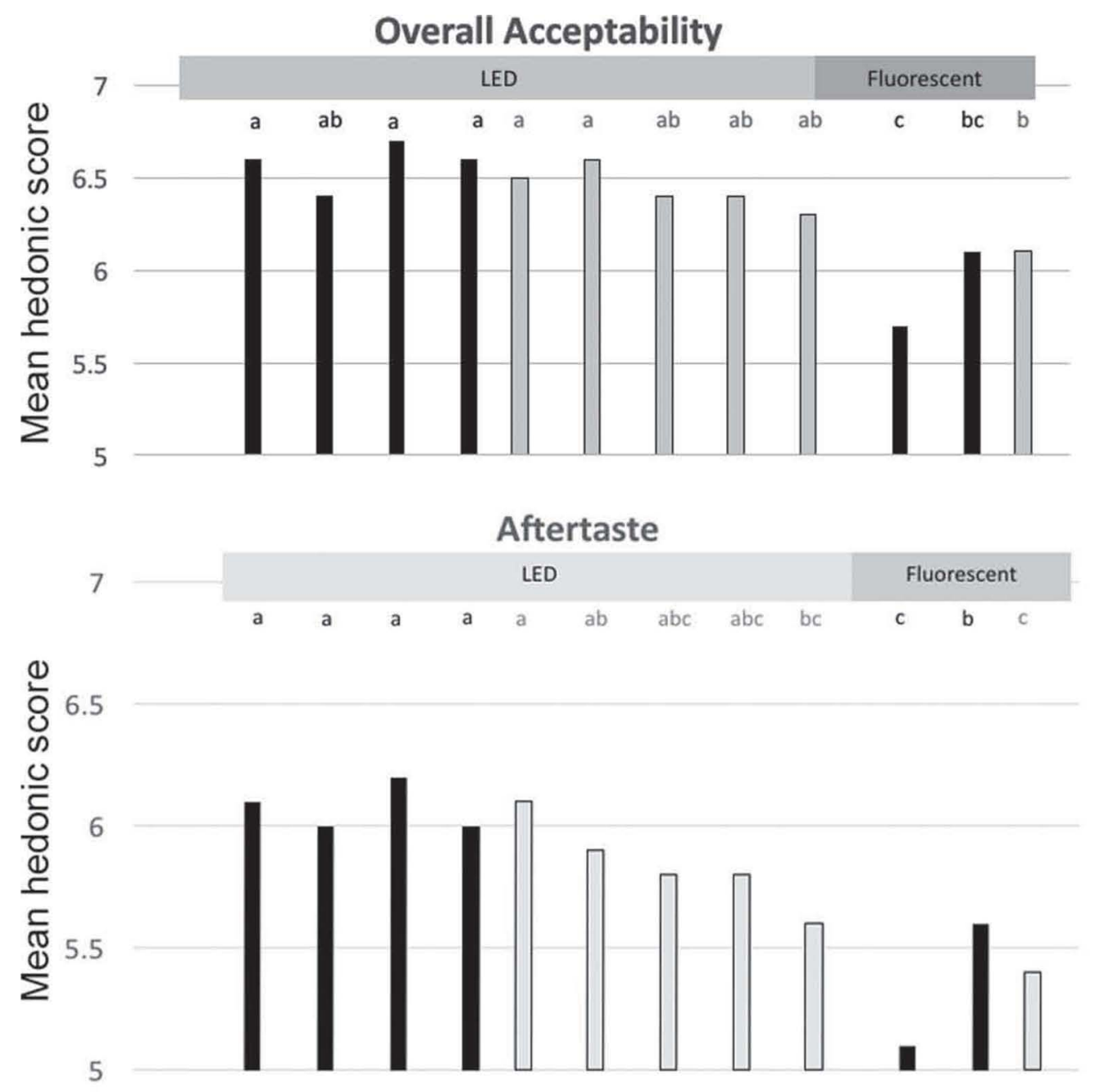

Freshness Perception

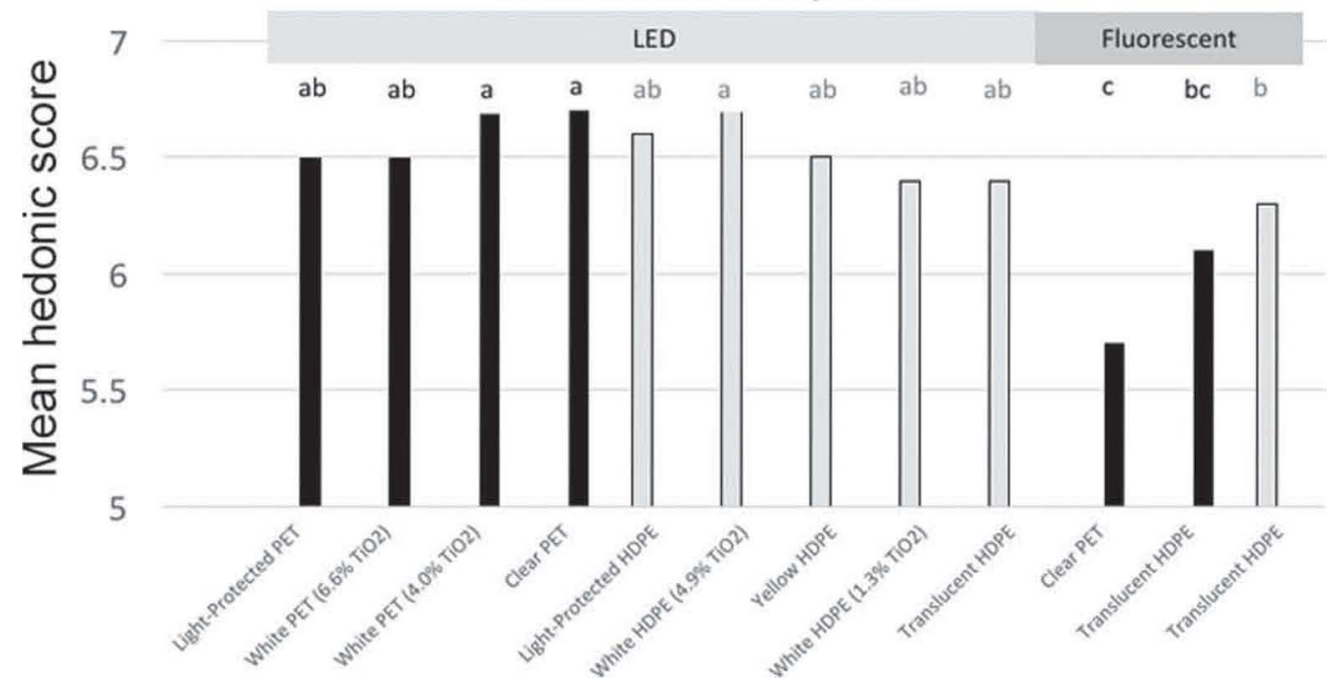

Figure 1. Overall acceptability, aftertaste acceptability, and freshness perception ( $1=$ dislike extremely; $9=$ like extremely) of $2 \%$ fluid milk, as influenced by packaging, after $4 \mathrm{~h}$ of exposure to light-emitting diode (LED) or fluorescent light in a refrigerated retail case (study 1: $960 \mathrm{~lx}$, gray; study 2: 1,460 lx, black). Letters with like colors were statistically compared; different letters indicate a difference at $P<0.05$. PET $=$ polyethylene terephthalate; HDPE = high-density polyethylene. 
While overall acceptability provides the overview, we also wished to provide some further understanding of how selected characteristics of milk might also influence consumer perception of milk. Appearance, mouthfeel, and aroma acceptability of milk did not differentiate between packaging or lighting conditions in the study using HDPE (study 1; Table 2). Differences were noted in the second study, especially related to lower acceptability in aroma and mouthfeel when milk in clear PET or translucent HDPE was exposed to fluorescent light (study 2; Table 2). Flavor acceptability and freshness perception closely mimicked the overall acceptabil- ity pattern, further validating the relationship among lighting, packaging efficacy, and consumer acceptance of fluid milk (Table 2; Figure 1).

Aftertaste acceptability offered additional information that helped further separate packaging and lighting influences. Products in PET exposed to LED lighting, with the higher light intensity of 1,460 lx, had higher acceptability for aftertaste (6.0 and higher) than did milk packaged in HDPE (except light-protected HDPE) under LED light. An interesting observation was that aftertaste acceptability of milk stored under fluorescent light was significantly lower. Further explanation of the
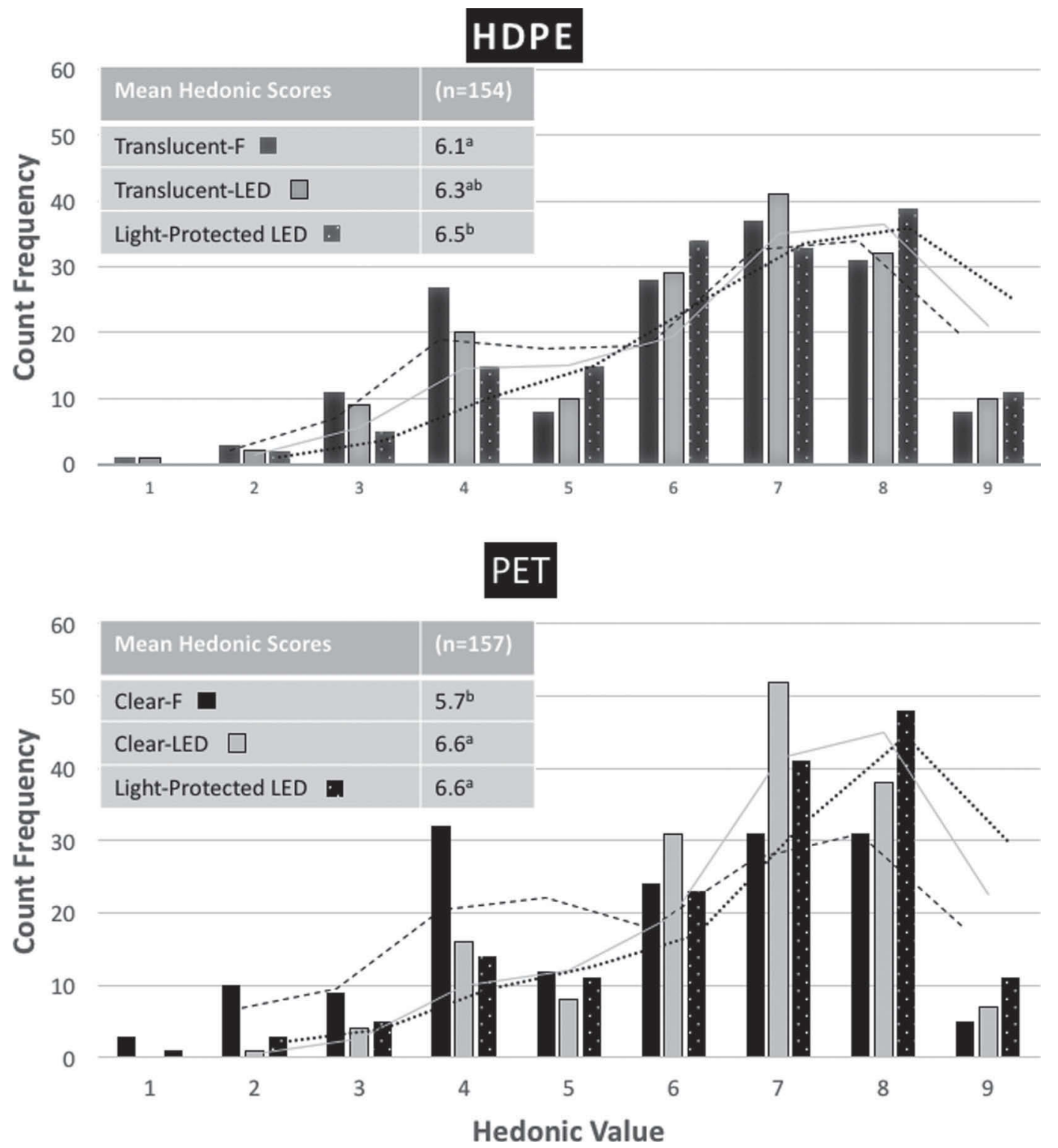

Figure 2. Histogram of overall acceptability on a 9-point hedonic scale $(1=$ dislike extremely; $9=$ like extremely $)$ when milk is packaged without light protection or in a light-protective package and exposed to light-emitting diode (LED) or fluorescent (F) light in a refrigerated retail case for $4 \mathrm{~h}$. HDPE $=$ high-density polyethylene; PET = polyethylene terephthalate. Mean hedonic scores (in inset tables) with different letters are significantly different $(P<0.05)$. Trend lines for HDPE: dashed black $=$ translucent-F; solid gray $=$ translucent-LED; dotted black $=$ light-protected-LED. Trend lines for PET: dashed black = clear-F; solid gray = clear-LED; dotted black = light-protected-LED. 
Table 2. Acceptability (mean scores ${ }^{1}$ ) of milk and milk attributes for milk packaged in high-density polyethylene $(\mathrm{HDPE})^{2}$ or polyethylene terephthalate $(\mathrm{PET})^{3}$ and exposed to light-emitting diode (LED) or fluorescent $(\mathrm{F})$ light for $4 \mathrm{~h}$

\begin{tabular}{|c|c|c|c|c|c|c|}
\hline Item & $\begin{array}{l}\text { Light-protected } \\
\text { HDPE (LED) }\end{array}$ & $\begin{array}{l}\text { High white } \\
\text { HDPE (LED) }\end{array}$ & $\begin{array}{c}\text { Yellow } \\
\text { HDPE (LED) }\end{array}$ & $\begin{array}{l}\text { Low white } \\
\text { HDPE (LED) }\end{array}$ & $\begin{array}{l}\text { Light-exposed } \\
\text { HDPE (LED) }\end{array}$ & $\begin{array}{l}\text { Light-exposed } \\
\operatorname{HDPE}(\mathrm{F})\end{array}$ \\
\hline $\begin{array}{l}\text { Study } 1(\mathrm{n}=154) ; \\
\text { light intensity }=960 \mathrm{~lx} \\
\text { Overall liking } \\
\text { Appearance liking } \\
\text { Aroma liking } \\
\text { Flavor liking } \\
\text { Mouthfeel liking } \\
\text { Aftertaste liking } \\
\text { Freshness perception } \\
\text { Aftertaste intensity }\end{array}$ & $\begin{array}{l}6.5^{\mathrm{a}} \\
7.1^{\mathrm{a}} \\
6.4^{\mathrm{a}} \\
6.5^{\mathrm{ab}} \\
6.6^{\mathrm{a}} \\
6.1^{\mathrm{a}} \\
6.6^{\mathrm{ab}} \\
2.3^{\mathrm{b}}\end{array}$ & $\begin{array}{l}6.6^{\mathrm{a}} \\
7.2^{\mathrm{a}} \\
6.4^{\mathrm{a}} \\
6.6^{\mathrm{a}} \\
6.6^{\mathrm{a}} \\
5.9^{\mathrm{ab}} \\
6.7^{\mathrm{a}} \\
2.5^{\mathrm{ab}}\end{array}$ & $\begin{array}{l}6.4^{\mathrm{ab}} \\
7.1^{\mathrm{a}} \\
6.4^{\mathrm{a}} \\
6.4^{\mathrm{abc}} \\
6.6^{\mathrm{a}} \\
5.8^{\mathrm{abc}} \\
6.5^{\mathrm{ab}} \\
2.5^{\mathrm{ab}}\end{array}$ & $\begin{array}{l}6.4^{\mathrm{ab}} \\
7.1^{\mathrm{a}} \\
6.3^{\mathrm{a}} \\
6.3^{\mathrm{abc}} \\
6.6^{\mathrm{a}} \\
5.8^{\mathrm{abc}} \\
6.4^{\mathrm{ab}} \\
2.6^{\mathrm{a}}\end{array}$ & $\begin{array}{l}6.3^{\mathrm{ab}} \\
7.0^{\mathrm{a}} \\
6.3^{\mathrm{a}} \\
6.2^{\mathrm{bc}} \\
6.4^{\mathrm{a}} \\
5.6^{\mathrm{bc}} \\
6.4^{\mathrm{ab}} \\
2.5^{\mathrm{ab}}\end{array}$ & $\begin{array}{l}6.1^{\mathrm{b}} \\
7.0^{\mathrm{a}} \\
6.2^{\mathrm{a}} \\
6.1^{\mathrm{c}} \\
6.4^{\mathrm{a}} \\
5.4^{\mathrm{c}} \\
6.3^{\mathrm{b}} \\
2.7^{\mathrm{a}}\end{array}$ \\
\hline \multirow{4}{*}{$\begin{array}{l}\text { Study } 2(\mathrm{n}=157) ; \\
\text { light intensity }=1,460 \mathrm{~lx} \\
\text { Overall liking } \\
\text { Appearance liking } \\
\text { Aroma liking } \\
\text { Flavor liking } \\
\text { Mouthfeel liking } \\
\text { Aftertaste liking } \\
\text { Freshness perception } \\
\text { Aftertaste intensity }^{4}\end{array}$} & $\begin{array}{l}\text { Light-protected } \\
\text { PET (LED) }\end{array}$ & $\begin{array}{l}\text { High white } \\
\text { PET (LED) }\end{array}$ & $\begin{array}{l}\text { Medium white } \\
\text { PET (LED) }\end{array}$ & $\begin{array}{l}\text { Light-exposed } \\
\text { PET (LED) }\end{array}$ & $\begin{array}{l}\text { Light-exposed } \\
\text { PET (F) }\end{array}$ & $\begin{array}{l}\text { Translucent } \\
\text { HDPE (F) }\end{array}$ \\
\hline & $6.6^{\mathrm{a}}$ & $6.4^{\mathrm{ab}}$ & $6.7^{\mathrm{a}}$ & $6.6^{\mathrm{a}}$ & $5.7^{\mathrm{c}}$ & $6.1^{\mathrm{bc}}$ \\
\hline & $6.5^{\mathrm{ab}}$ & $6.5^{\mathrm{ab}}$ & $6.8^{\mathrm{a}}$ & $6.7^{\mathrm{a}}$ & $5.7^{\mathrm{c}}$ & $6.1^{\mathrm{bc}}$ \\
\hline & $2.4^{\mathrm{b}}$ & $2.5^{\mathrm{b}}$ & $2.4^{\mathrm{b}}$ & $2.4^{\mathrm{b}}$ & $2.9^{\mathrm{a}}$ & $2.6^{\mathrm{b}}$ \\
\hline
\end{tabular}

${ }^{\mathrm{a} c}$ Means with different letters within a row are significantly different $(P<0.05)$.

${ }^{1} 1=$ dislike extremely; $5=$ neither like nor dislike; $9=$ like extremely.

${ }^{2}$ Light-protected HDPE package wrapped in foil and plastic for complete light block; high white $\mathrm{HDPE}$ : $4.9 \%$ TiO ${ }_{2}$; yellow $\mathrm{HDPE}$ : commercially available masterbatch; low white HDPE: $1.3 \% \mathrm{TiO}_{2}$; light-exposed HDPE: translucent $\mathrm{HDPE}\left(0 \% \mathrm{TiO}_{2}\right)$.

${ }^{3}$ Light-protected PET packaged wrapped in foil and plastic for complete light block; high white PET: $6.6 \%$ TiO ${ }_{2}$; medium white PET: $4.0 \%$ $\mathrm{TiO}_{2}$; light-exposed PET: clear (no UV block or $\mathrm{TiO}_{2}$ ).

${ }^{4} 1=$ no aftertaste; $3=$ moderately strong aftertaste; $5=$ extremely strong aftertaste.

importance of packaging on the influence of consumer acceptance is that milk in yellow HDPE, low white HDPE, and translucent HDPE under LED lighting had aftertaste acceptability scores that were not different $(P>0.05)$ from the milk packaged in translucent HDPE under fluorescent lighting. Whereas the initial overall acceptability profile of milk suggested that LED lighting had less effect on milk acceptability and packaging seemed to be equally effective, the role of effective levels of light-protective additives and, potentially, sufficient oxygen barrier properties may be valuable in protecting milk quality and helping maintain consumer acceptance at these early stages of product shelf-life. Implications of light exposure on consumer intention to drink milk may relate to more than overall acceptability. The emotional experience associated with consuming beverages and foods plays an important role in how consumers perceive products (Schifferstein et al., 2013). With light exposure, consumer impression of fresh milk experience may include the emotion disgust, related to light-induced oxidation flavors that overwhelm the bland, slightly sweet flavor of fresh milk. Disgust is recognized as an emotion associated with food rejection and develops as a response to bad smell and taste of food (Rozin et al., 1997). Arnade et al. (2013) described the emotions expressed by college students after tasting unflavored and chocolate-flavored milk. Products were purchased directly from the retail case [unflavored milk in translucent HDPE; chocolate milk in HDPE package with light protective additives (LPA)] in a local supermarket, thus representing the experience that most consumers would receive. The emotional experience for the unflavored milk was frequently described as disgust, a term that was not applied to drinking chocolate milk. Walsh et al. (2015) further clarified that college students more frequently used the term disgust when milk had received light exposure. Many low energy but positive terms such as content, calm, good, happy, pleased, and interested were frequently selected from fresh milk (received directly from the retail dairy case manager when delivered to store). After extensive light exposure (375 lx, $7 \mathrm{~d}$ ), selection of these positive terms was significantly reduced, whereas milk protected from light for the same duration continued to elicit these positive emotions. When milk is disliked (low hedonic score), worried becomes a more frequently selected term (Walsh et al., 2015).

Consumers were also asked to rate the flavor of milk scored on a JAR scale ( 1 or $2=$ too little, $3=$ just right, 4 or $5=$ too much) and these results were related 


\section{Study 1 Not Enough Study $2 \square$ Not Enough}

$\begin{array}{ll}\text { - Just About Right } & \boxminus \text { Too Much } \\ \text { - Just About Right } & \text { - Too Much }\end{array}$

\section{Flavor: Just About Right}

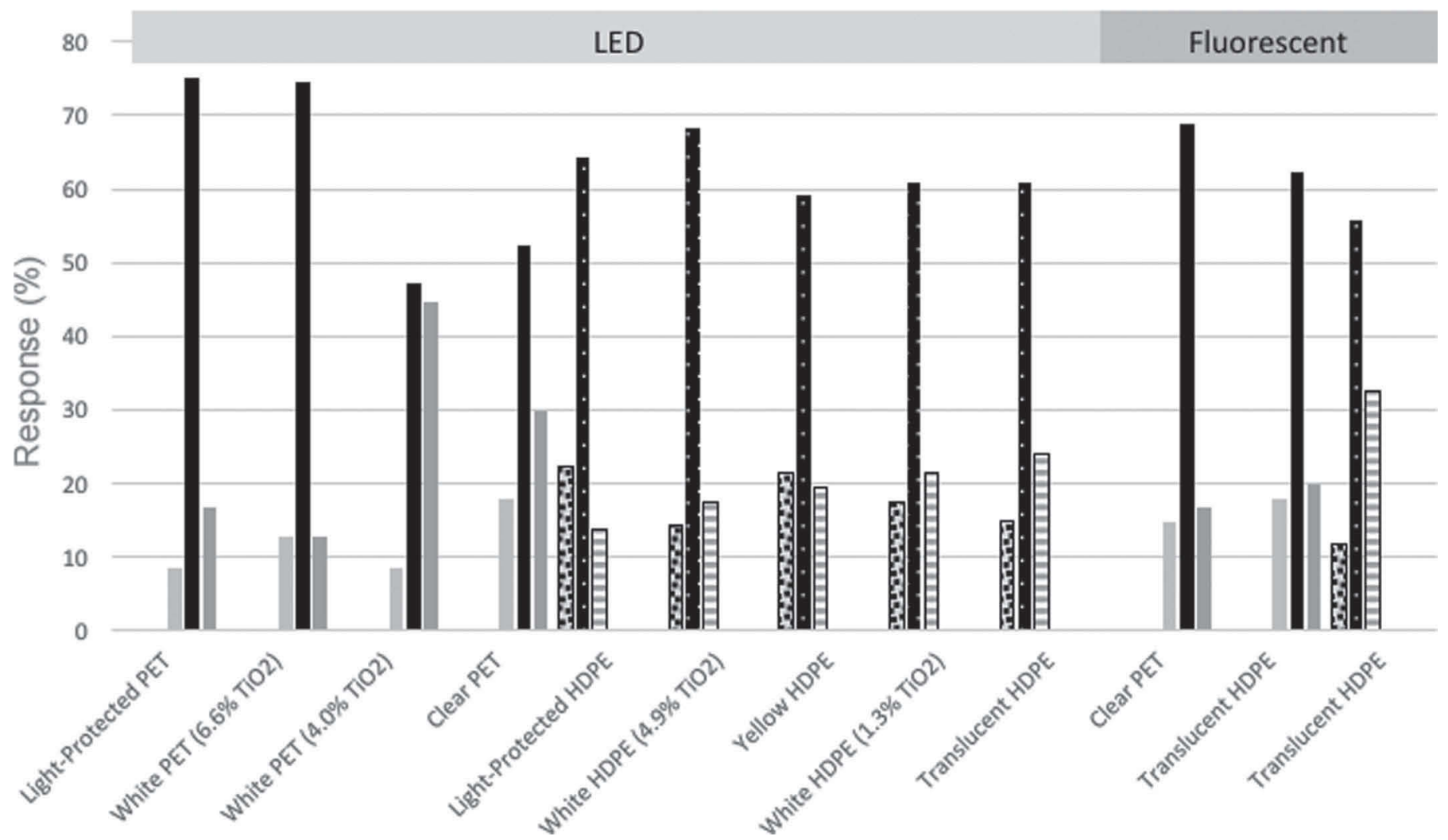

Figure 3. Just-about-right responses to $2 \%$ milk packaged in high-density polyethylene (HDPE) or polyethylene terephthalate (PET) under light-emitting diode (LED) and fluorescent lighting in a refrigerated retail case.

to overall acceptability scores using a penalty analysis (Figure 3). When milk was perceived to have "too much" flavor, this led to a 1.8 to 2.5 point decrease in acceptability scores for the low white $\left(1.3 \% \mathrm{TiO}_{2}\right)$ HDPE and light-exposed translucent HDPE under fluorescent and LED light. When panelists thought milk had "too little" flavor, it decreased their acceptability scores for milk packaged in the yellow HDPE and lightprotected HDPE control under LED light. However, the decrease in acceptability due to "too little" flavor was only 1.0 to 1.3 points. Panelists who thought milk stored in the clear PET under fluorescent light had too much flavor rated the overall acceptability of this milk 2.5 integers lower than panelists who thought this milk sample's flavor was just right. Having "too much" flavor was a more serious fault for high quality milk, which is supposed to taste bland and slightly sweet with little to no aftertaste (Alvarez, 2009). An increase in oxidation that resulted in more extensive oxidized off-flavors could be the cause of consumers' perception of milk having "too much" flavor compared with their ideal for high quality milk.

Changes occurred in milk that affected flavor and quality after as little as $4 \mathrm{~h}$ of light exposure, which were noticeable to untrained consumer panelists and had direct influence on overall acceptability of the milk stored in these conditions. These results demonstrate that milk stored under LED light has clear advantages for maintaining consumer acceptance over milk stored under fluorescent light. This study found higher acceptability scores than were reported by Brothersen et al. (2016) for 1\% milk stored under higher intensity LED light $(4,000 \mathrm{~lx})$ for 12 or $24 \mathrm{~h}$ (hedonic score $=5.9$ and 5.4, respectively). Higher light intensity and longer durations of light exposure have the potential to decrease consumer acceptance of milk. Light interference properties in packaging may provide more significant protection to maintain consumer acceptance if milk was 
stored under higher intensity lights for longer durations of time.

\section{Analytical Assessment of Light-Induced Oxidation}

Available oxygen in milk is used up as a reactant by photosensitizers that are excited by light to initiate oxidation. When oxygen is consumed by oxidation reactions, the levels of DO in milk decrease. Dissolved oxygen content was measured in this study and served as a reliable indicator of noticeable sensory changes due to oxidation (Table 3). Dissolved oxygen decreased more in milk exposed to fluorescent light than in milk exposed to LED light. Both HDPE and LED light-protected control packages had higher levels of DO than all other packages stored under LED or fluorescent light. Dissolved oxygen levels were not different in the other HDPE (study 1) or PET (study 2) treatment packages under LED light. The light-exposed HDPE package and the light-exposed clear PET package under fluorescent light had the lowest DO levels, indicating the most extensive oxidation. We suggest that the wavelengths absorbed by $\mathrm{Rb}$ and other molecules during fluorescent light exposure initiated more extensive oxidation reactions than LED light exposure. The packages with greater pigmentation blocked more light exposure and prevented light-induced oxidation reactions from being as extensive as in the unpigmented packages that provided little to no light protection.

The TBARS assay measures the formation of aldehydes and other secondary oxidation byproducts that are produced from oxidation reactions and have been used as an indicator of light-induced oxidation in extended shelf-life fluid milk for up to $35 \mathrm{~d}$ (Johnson et

Table 3. Dissolved oxygen (ppm; mean and SE) in milk packaged in high-density polyethylene (HDPE) and polyethylene terephthalate (PET) after exposure to light-emitting diodes (LED) and fluorescent lighting for $4 \mathrm{~h}$

\begin{tabular}{llcc}
\hline HDPE Package Treatment & Light & \multicolumn{2}{c}{ Dissolved oxygen (ppm) } \\
\hline Study 1 $(960 \mathrm{~lx})$ & & Mean & $\pm \mathrm{SE}$ \\
Light-protected & LED & $11.29^{\mathrm{a}}$ & 0.04 \\
High $\left(4.9 \% \mathrm{TiO}_{2}\right)$ & LED & $10.88^{\mathrm{b}}$ & 0.10 \\
Yellow & LED & $10.99^{\mathrm{b}}$ & 0.07 \\
Low $\left(1.3 \% \mathrm{TiO}_{2}\right)$ & LED & $10.86^{\mathrm{b}}$ & 0.07 \\
Light-exposed & LED & $10.78^{\mathrm{b}}$ & 0.05 \\
Light-exposed & Fluorescent & $10.41^{\mathrm{c}}$ & 0.06 \\
Study 2 (1,460 lx) & & & \\
Light-protected PET & LED & $10.78^{\mathrm{a}}$ & 0.12 \\
High $\left(6.6 \% \mathrm{TiO}_{2}\right)$ PET & LED & $10.76^{\mathrm{b}}$ & 0.05 \\
Medium $\left(4.0 \% \mathrm{TiO}_{2}\right)$ PET & LED & $10.78^{\mathrm{b}}$ & 0.05 \\
Light-exposed PET & LED & $10.54^{\mathrm{b}}$ & 0.07 \\
Light-exposed PET & Fluorescent & $9.42^{\mathrm{b}}$ & 0.12 \\
Light-exposed HDPE & Fluorescent & $10.24^{\mathrm{c}}$ & 0.07 \\
\hline
\end{tabular}

${ }^{a-c}$ Means with different letters are significant different $(P<0.05)$. al., 2015). However, in this experiment using HTSTpasteurized milk receiving only $4 \mathrm{~h}$ of light exposure, very low levels of secondary oxidation byproducts were found $(0.16-0.19 \mathrm{mg} / \mathrm{L}$ in study $1 ; 0.14-0.22 \mathrm{mg} / \mathrm{L}$ in study 2 ; data not presented). No differences $(P>0.05)$ were found in aldehyde levels between any of the treatment packages in either study. These levels are much lower than what has been reported in previous research, indicating that a more sensitive methodology may be necessary to detect early oxidation changes that are occurring after short periods of light exposure.

Because $\mathrm{Rb}$ is a photosensitive vitamin found in relatively high quantities in milk, its degradation has been used as a measure of oxidation in previous research (Webster et al., 2009; Johnson et al., 2015). However, the oxidation that occurred in this study after only 4 $\mathrm{h}$ of light exposure was limited. No differences $(P>$ 0.05 ) were found between $\mathrm{Rb}$ content in milk stored in different packages in study 1 or study 2 (data not presented). The Rb content of milk in study 1 was between 1.04 and $1.49 \mathrm{mg} / \mathrm{L}$ and between 1.44 and 1.46 $\mathrm{mg} / \mathrm{L}$ for study 2 . These values are within range of previously reported $\mathrm{Rb}$ content for $2 \%$ milk (1.36-1.75 mg/L; Dimick, 1982; Gebhardt and Thomas, 2002; Zygoura et al., 2004; Brothersen et al., 2016), suggesting this methodology does not serve as the most accurate indication of light-induced oxidation under the conditions of this study.

\section{CONCLUSIONS}

Changes in milk quality and flavor occur rapidly during light exposure, affecting consumer perception of milk quality after as little as $4 \mathrm{~h}$ of light exposure. Different types of light affect the extent of oxidation reactions in milk, with low level LED light initiating less oxidation than fluorescent light of similar intensity. These changes in milk quality are noticeable to consumers and cause consumers to rate the acceptability of milk stored under fluorescent light lower than milk stored under LED light. Changes in DO content may serve as a more reliable analytical measurement of early oxidation reactions in milk stored under LED light than traditional analytical methods. Retailers should consider light source as a factor influencing the quality of packaged foods. The use of low intensity LED lights until the point of consumer purchase may be helpful in maintaining the highest milk quality and perception of freshness during those periods of rapid product turnover. All HDPE and PET packages were effective at maintaining high quality milk under $4 \mathrm{~h}$ of lowintensity LED light, but effective pigmentation levels of packaging materials, especially in HDPE packaging, 
may be necessary to protect milk from detrimental light exposure over longer storage durations or higher intensity lighting conditions.

\section{ACKNOWLEDGMENTS}

This project was funded in part by the National Dairy Council (Rosemont, IL), Midwest Dairy Council (St Paul, MN), the Virginia Agricultural Experiment Station, and the Hatch Program of the National Institute of Food and Agriculture, USDA. Packaging was provided by Chemours (Wilmington, DE) and the retail case was provided by HillPhoenix (Chesterfield, VA).

\section{REFERENCES}

Alvarez, V. 2009. Fluid milk and cream products. Pages $73-134$ in The Sensory Evaluation of Dairy Products. 2nd ed. S. Clark, M. Costello, M. Drake, and F. Bodyfelt, ed. Springer Science and Business Media, New York, NY.

AOAC International. 1995. AOAC Official Method 970.65. Riboflavin (Vitamin $\mathrm{B}_{2}$ ) in foods and vitamin preparations-fluorometric method. AOAC Official Methods of Analysis. 9-10.

Arnade, E. A., S. E. Duncan, R. Rudd, J. Dunsmore, and S. O'Keefe 2013. Characterizing consumer emotional response to flavored and unflavored milk through an emotion-based questionnaire. J. Dairy Sci. 96(E-Suppl. 1):39 (Abstr. T108).

Bauer, A. 2016. A burst of flavor leads fluid milk sales. Hoard's Dairyman. Accessed Feb. 17, 2016. http://hoards.com/article17898-A-burst-of-flavor-leads-fluid-milk-sales.html.

Brothersen, C., D. J. McMahon, J. Legako, and S. Martini. 2016. Comparison of milk oxidation by exposure to LED and fluorescent light. J. Dairy Sci. 99:2537-2544.

Chapman, K. W., L. J. Whited, and K. J. Boor. 2002. Sensory threshold of light-oxidized flavor defects in milk. J. Food Sci. 67:27702773.

Cochran, W. G., and G. W. Snedecor. 1980. Statistical Methods. 7th ed. Iowa State University Press, Ames. 15:279-280.

Dimick, P. S. 1982. Photochemical effects on flavor and nutrients of fluid milk. Can. Inst. Food Sci. Technol. 15:247-256.

Duncan, S. E., and J. B. Webster. 2010. Oxidation and protection of milk and dairy products. Woodhead Publishing, Ltd., Cambridge, UK.

Gebhardt, S. E., and R. G. Thomas. 2002. Nutritive Values of Foods United States Department of Agriculture, Agricultural Research Service. Home and Garden Bulletin 72:18-22.

Heer, A. K., S. E. Duncan, and D. Brochetti. 1995. Sensory detection of and consumer response to off-flavors in milk. Dairy Food Environ. Sanit. 15:488-493.

Johnson, D. S., S. E. Duncan, L. M. Bianchi, H. H. Chang, W. N. Eigel, and S. F. O'Keefe. 2015. Packaging modifications for protecting flavor of extended-shelf-life-milk from light. J. Dairy Sci. 98:2205-2214.
Keith, M. A. 2005. What does the date on the milk jug mean? Hillsborough County Family and Consumer Sciences Newsletter, University of Florida Extension, Institute of Food and Agricultural Sciences. October. Accessed Jun. 28, 2016. http://hillsborough. ifas.ufl.edu/documents/pdf/fcs/newsletters/2005_10NL.pdf.

Laird, D. T., S. A. Gambrel-Lenarz, F. M. Scher, T. E. Graham, and R. Reddy. 2004. Microbiological count methods. Page 153 in Standard Methods for the Examination of Dairy Products. 17th ed. H. M. Wehr and J. F. Frank, ed. American Public Health Association, Washington, DC

Martin, N., N. Carey, S. Murphy, D. Kent, J. Bang, T. Stubbs, M. Wiedmann, and R. Dando. 2016. Exposure of fluid milk to lightemitting diode light negatively affects consumer perception and alters underlying sensory properties. J. Dairy Sci. 99:4306-4324.

Meilgaard, M. C., G. V. Civille, and B. T. Carr. 2007. Sensory Evaluation Techniques. Taylor \& Francis Group, CRC Press, Boca Raton, FL.

Mestdagh, F., B. D. Meulenaer, J. D. Clippeleer, F. Devlieghere, and A. Huyghebaert. 2005. Protective influence of several packaging materials on light oxidation of milk. J. Dairy Sci. 88:499-510.

Peryam, D. R. 1957. The 9-point hedonic scale: Dr. David R. Peryam's early papers on the most widely used sensory scale in the world. Peryam \& Kroll Research Corporation. Accessed Feb. 7, 2015. http://www.pkresearch.com/services/media/ paperandpublications/theninepointhedonicscale-papers.pdf.

Potts, H. L., S. E. Duncan, M. L. Johnson, S. F. O'Keefe, J. E. Marcy, and K. Mallikarjunan. 2016. Oxygen barrier and light interference packaging properties for controlling light-induced oxidation in milk. J. Dairy Sci. 99(E-Suppl. 1):334. (Abstr.)

Rozin, P., J. Haidt, C. R. McCauley, and S. Imada. 1997. The cultural evolution of disgust. Pages 65-82 in Food Preferences and Taste: Continuity and Change. H. M. Macbeth, ed. Berghahn, Oxford, UK.

Schifferstein, H. N. J., A. Fenko, P. M. A. Desmet, D. Labbe, and N. Martin. 2013. Influence of package design on the dynamics of multisensory and emotional food experience. Food Qual. Prefer. $27: 18-25$.

Spanier, A. M., and R. D. Traylor. 1991. A rapid, direct chemical assay for the quantitative determination of thiobarbituric acid reactive substances in raw, cooked, and cooked/stored muscle foods. Muscle Foods 2:165-176.

USDA. 2015. Food product dating. Accessed Jun. 28, 2016. http:// www.fsis.usda.gov/wps/portal/fsis/topics/food-safety-education/ get-answers/food-safety-fact-sheets/food-labeling/food-productdating/food-product-dating.

Walsh, A. M., S. E. Duncan, H. L. Potts, and D. L. Gallagher. 2015 Comparing quality and emotional responses as related to acceptability of light-induced oxidation flavor in milk. Food Res. Int. 76:293-300.

Webster, J. B., S. E. Duncan, J. E. Marcy, and S. F. O'Keefe. 2009 Controlling light oxidation flavor in milk by blocking riboflavin excitation wavelengths by interference. J. Food Sci. 74:S390-S398.

White, C. H. 1985. Consumer reaction to colored plastic milk jugs. J. Dairy Sci. 68:261-264.

Zygoura, P., T. Moyssiadi, A. Badeka, E. Kondyli, I. Savvaidis, and M. G. Kontominas. 2004. Shelf life of whole pasteurized milk in Greece: Effect of packaging material. Food Chem. 87:1-9. 